\title{
Adsorption and Desorption of Emerging Water Contaminants on Activated Carbon Fabrics
}

\author{
Sandrine Delpeux-Ouldriane1, Mickaël Gineys¹, Nathalie Cohaut, François Béguin1, \\ Sylvain Masson², Laurence Reinert ${ }^{2}$, Laurent Duclaux ${ }^{2}$ \\ ${ }^{1}$ CNRS-Université d'Orléans, ICMN \\ 1B Rue de la Férollerie, Orléans, France, 45071 \\ delpeux@cnrs-orleans.fr \\ 2Université Savoie Mont Blanc, LCME \\ Chambéry, France, 73000 \\ laurent.duclaux@univ-savoie.fr
}

\begin{abstract}
Nowadays, a wide variety of organic contaminants is present at trace concentrations in wastewater effluents. In order to mitigate these pollution problems, the implementation of the REACH European regulation has defined lists of targeted pollutants to be eliminated selectively in water. This therefore implies the development of innovative and more efficient remediation techniques. In this regard, adsorption processes can be successfully used to achieve the removal of organic compounds in waste water treatment processes, especially at low pollutant concentration. Activated carbons possess a highly developed porosity and thus demonstrate high adsorption capacities. More specifically, carbon cloths show high adsorption rates, ease of handling, good mechanical integrity and regeneration potential. When loaded with pollutants, these materials can be regenerated using electrochemical polarization.
\end{abstract}

Keywords: Nanoporous carbons, activated carbon cloths, adsorption, micropollutants, emerging contaminants, regeneration, electrochemistry.

(C) Copyright 2015 Authors - This is an Open Access article published under the Creative Commons Attribution License terms (http://creativecommons.org/licenses/by/3.0). Unrestricted use, distribution, and reproduction in any medium are permitted, provided the original work is properly cited.

\section{Introduction}

A wide variety of organic compounds that are used in domestic, agricultural and industrial applications are present at trace concentrations in wastewater effluents [1, 2]. These micropollutants include personal-care products, plasticizers, reproductive hormones, pesticides and pharmaceuticals [3]. The adsorption properties of activated carbons offer great potential for water purification, particularly in the case of tertiary treatments as they are the most prevalent and competitive adsorbents, especially at low pollutant concentration. However, the major disadvantage encountered is their short lifetime due to the low and expensive regeneration capacities. Generally, the loaded carbon adsorbent can be regenerated ex-situ through high energy-consuming processes, like thermal treatments or steaming.

Specifically, as compared to powder or granules, activated carbon cloths (ACC) show numerous advantages, thanks their ease of handling, high mechanical integrity and regeneration potential. Additionally, due to their microtexture and their small fiber diameters (around $10 \mu \mathrm{m}$ ), they are ideal candidates for adsorption purposes as they show minimal diffusion limitation and greater adsorption rates towards noxious organic pollutants [4].

In the present work, the adsorption properties of some micropollutants and emerging pollutants, especially pharmaceutical residues, were investigated using an activated carbon cloth. Electrochemical polarization was applied to achieve the reversible desorption of adsorbed species and the regeneration of the adsorbent porosity [5, 6].

The involved mechanisms were carefully examined and correlated to the nanoporous texture of the adsorbent by taking into account the adsorbate speciation and physico-chemical properties. Results 
show that the reversible electrochemical desorption of the induced charged molecules offers great promise. Such systems could find a place of choice in industrial processes for tertiary treatment and for the treatment of hospital effluents, but also for underground water exploitation [7].

\section{Experimental}

\section{1. Adsorbent}

An activated carbon cloth possessing a highly developed surface area was used (Table 1). Its porous network consisted of a large amount of supermicropores $(0.7-2 \mathrm{~nm})$ and ultramicropores $(<0.7$ $\mathrm{nm})$. The pore size distribution was very narrow and centered at 1-1.2 nm.

Table 1. Microtextural adsorbent characteristics.

\begin{tabular}{|c|c|c|c|c|c|}
\hline $\begin{array}{c}\mathrm{S}_{\text {BET }} \\
\left(\mathrm{m}^{2} / \mathrm{g}\right)\end{array}$ & $\begin{array}{c}\mathrm{V}_{\text {MICRO }} \\
\mathrm{N}_{2}, \mathrm{DFT} \\
\left(\mathrm{cm}^{3} / \mathrm{g}\right)\end{array}$ & $\begin{array}{c}\mathrm{V}_{\text {MESO }} \\
\mathrm{N}_{2}, \mathrm{DFT} \\
\left(\mathrm{cm}^{3} / \mathrm{g}\right)\end{array}$ & $\begin{array}{c}\mathrm{V}_{\text {MICRO }} \\
\mathrm{N}_{2}, \mathrm{DR} \\
\left(\mathrm{cm}^{3} / \mathrm{g}\right)\end{array}$ & $\begin{array}{c}\mathrm{V}_{\text {MICRO }} \\
\mathrm{CO}_{2}, \mathrm{DR} \\
\left(\mathrm{cm}^{3} / \mathrm{g}\right)\end{array}$ & $\begin{array}{c}\mathrm{V}_{\text {TOTAL }} \\
\mathrm{N}_{2} \\
\left(\mathrm{~cm}^{3} / \mathrm{g}\right)\end{array}$ \\
\hline 1175 & 0.59 & 0.09 & 0.57 & 0.57 & 0.68 \\
\hline
\end{tabular}

This material was rather hydrophobic and contained $95 \%$ (mass \%) of carbon and 1.2\% of oxygen. It presented a basic zero charge $\mathrm{pH}(8.9)$ and a low amount of oxygenated surface groups $(0.2$ $\mathrm{mmol} / \mathrm{g}$ ). The diameters of the fibers were in the range of ten micrometers and micropores were directly accessible all along the fibers (Figure 1).

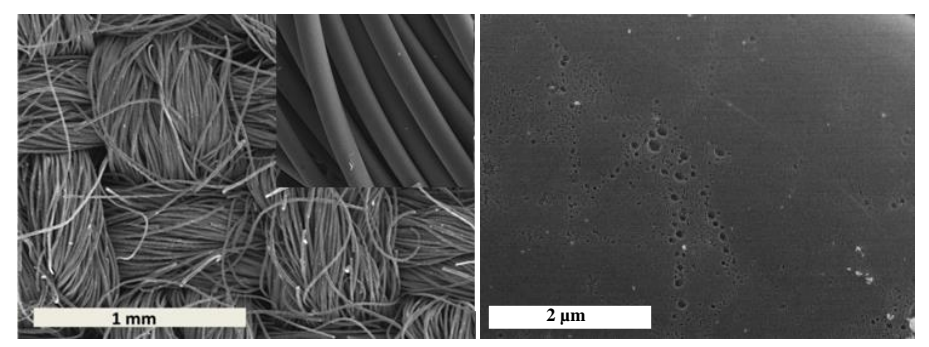

Figure 1. SEM images of the activated carbon cloth.

\section{2. Targeted Pollutants}

Seven organic molecules, diclofenac (DFN), caffeine (CAF), acetaminophen (also called paracetamol POL), bisphenol A (BPA), carbamazepine (CBZ), pentachlorophenol (PCP) and ofloxacin (OFX) were selected (Figure 2).

These contaminants possess different physicochemical properties: water solubility, polarity, $\mathrm{pK}_{\mathrm{A}}$ values, and molecular volumes (Table 2).

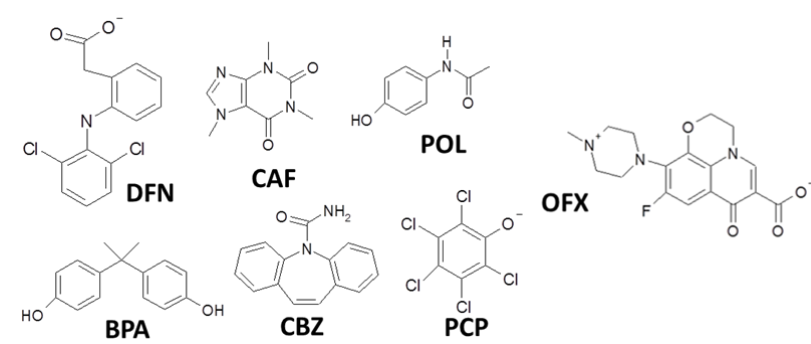

Figure 2. Adsorbates formulae and speciations at pH 7.5.

Table 2. Pollutants characteristics at pH7.5.

\begin{tabular}{|c|c|c|c|c|}
\hline & $\mathrm{pK}_{\mathrm{A} 1} / \mathrm{pK}_{\mathrm{A} 2}$ & $\mathrm{~V}\left(\AA^{3}\right)$ & $\mathrm{s}(\mathrm{mmol} / \mathrm{L})$ & $\mathrm{Log} \mathrm{K}_{\mathrm{ow}}$ \\
\hline POL & 9.5 & 138 & 74.0 & 1.08 \\
\hline PCP & 5.0 & 144 & 5.7 & 1.90 \\
\hline CAF & 0.6 & 340 & 225.2 & -0.79 \\
\hline CBZ & $2.3 / 13.9$ & 400 & 0.2 & 3.22 \\
\hline BPA & 9.8 & 460 & 0.7 & 4.32 \\
\hline DFN & 4.0 & 580 & 154.1 & 0.55 \\
\hline OFX & $5.5 / 8.2$ & 850 & 144.5 & -0.93 \\
\hline
\end{tabular}

\section{3. Analytical Detection and Quantification}

Reverse phase HPLC was used to perform the detection and the quantification during adsorption kinetics, in binary or complex mixture and isotherm adsorption. The chromatographic separation was performed in the reversed phase mode using a Hypersil Gold $\mathrm{C}_{18}$ column at $25^{\circ} \mathrm{C}(100 \times 2.1 \mathrm{~mm}$ with a particle size of $3 \mu \mathrm{m}$ ). The eluents were water (A) at $\mathrm{pH} 2.9$ through acidification by orthophosphoric acid $0.01 \%$ $(\mathrm{v} / \mathrm{v})$ and acetonitrile (B). The following multi-step linear gradient was applied: from $10 \% \mathrm{~B}$ to $80 \% \mathrm{~B}$ in $25.45 \mathrm{~min}$ (slope of $2.75 \mathrm{~mL} / \mathrm{min}$ ), followed by a plateau for 2 min then a decrease from $80 \%$ B to $10 \%$ $\mathrm{B}$ in one minute and a final plateau of $3 \mathrm{~min}$ at the initial conditions. The flow rate was set to $0.25 \mathrm{ml} / \mathrm{min}$ and the volume of injection to $50 \mu \mathrm{L}$ [8].

\section{4. Adsorption Measurements}

All the kinetics studies were conducted in a phosphate buffer at $\mathrm{pH}$ 7.5. In the case of binary mixtures, a total concentration of $10^{-4} \mathrm{~mol} / \mathrm{L}$ was set $\left(5.10^{-5} \mathrm{~mol} / \mathrm{L}\right.$ per each pollutant). For the complex mixture, a total concentration of $10^{-4} \mathrm{~mol} / \mathrm{L}$ was set $\left(1.43 .10^{-5} \mathrm{~mol} / \mathrm{L}\right.$ per each pollutant). The kinetics data were fitted with the pseudo second order model.

The adsorption isotherms were studied at 13, 25 and $40^{\circ} \mathrm{C}$ for DFN, CAF, CBZ, BPA and OFX. Experimentally, stoppered vials containing disks of carbon adsorbent (12 mg) were placed in $50 \mathrm{~mL}$ pollutant solution at various concentrations (from 
about $10^{-5}$ to $10^{-3} \mathrm{~mol} / \mathrm{L}$ ) and stirred until equilibrium was reached. The equilibrium time was strongly dependent of the pollutants nature. For some molecules, seven days were sufficient, except for OFX (21 days), DFN (14 days) and PCP (10 days). The solutions prepared at a given concentration were exactly the same for each of the three temperatures in order to obtain precise and comparable results. The solutions were filtered on $0.45 \mu \mathrm{m}$ filter membranes prior to HPLC analysis.

\section{5. Regeneration Under Polarization}

Regeneration was performed using a classical three electrode system connected to a galvanostat/potentiostat (VMP-1, Biologic) in a 0.01 mol. $\mathrm{L}^{-1} \mathrm{Na}_{2} \mathrm{SO}_{4}$ electrolyte $\left(\mathrm{pH}=5.9\right.$ and $\sigma=2.5 \mathrm{mS} . \mathrm{cm}^{-}$ $1)$. After adsorption in open circuit voltage (OCV), the loaded ACC disk was washed with ultra-pure water $\left(\sigma_{\text {water }}=0,055 \mu \mathrm{S} . \mathrm{cm}^{-1}\right)$ and attached to a current collector for the electro-desorption experiments. A counter electrode and $\mathrm{Hg} / \mathrm{Hg}_{2} \mathrm{SO}_{4}(\mathrm{E}=0.649 \mathrm{~V}$ vs NHE$)$ as reference electrode were used. Negative currents $(-$ $10 \mathrm{~mA}$ ) were applied to the activated carbon cloth electrode $[7,9]$.

\section{Results and Discussion}

\section{1. Adsorption Isotherms}

Isotherms were studied at $298 \mathrm{~K}$ (not shown) in order to calculate the Gibbs free energy variation $\Delta \mathrm{G}^{0}{ }_{298 \mathrm{~K}}$ at a maximum uptake for the adsorption of five molecules on the carbon fabric (Table 3). All the isotherms except that of OFX were simulated using the Langmuir-Freundlich equation Eq. 1 as:

$Q_{e}=Q_{\max } \times\left(K_{l f} C_{e}\right)^{n} /\left(1+\left(K_{l f} C_{e}\right)^{n}\right.$

where $Q_{e}$ is the adsorption uptake at equilibrium (mmol/g), $C_{e}$ is the concentration at equilibrium (mmol/L), $k_{l f}$ is the Langmuir-Freundlich constant (L/mmol), $Q_{\max }$ is the maximum uptake $(\mathrm{mmol} / \mathrm{g}$ ) and $n$ is the Langmuir-Freundlich exponent.

The OFX and BPA isotherms were better simulated by a Langmuir model for which the $n$ exponent values were equal to one in the previous equation (Table 2).

The Gibbs free energy variations $\Delta \mathrm{G}^{0}{ }_{298 \mathrm{~K}}$ were determined from Eq. 2 as:
$\Delta G^{0}{ }_{T}=-R T \ln (K)$

where $\mathrm{R}$ is the ideal gas constant, $\mathrm{T}$ the temperature $(\mathrm{K})$ and $K$ the equilibrium constant (estimated from the relation $K=\mathrm{C}_{\mathrm{ads}} / \mathrm{C}_{\mathrm{e}}$, where $C_{a d s}$ is the concentration adsorbed at equilibrium in $\mathrm{mmol} / \mathrm{L}$ ).

In order to compare the $\Delta \mathrm{G}^{0}{ }_{298 \mathrm{~K}}$ values of the different adsorbates, they were calculated at the $Q_{e}$ uptake value equal to $80 \%$ of $Q_{\max }$ for each isotherm. Negative and small $\Delta \mathrm{G}^{0}$ showed a spontaneous and physical adsorption process. $\Delta \mathrm{G}^{0}$ values are discussed in section 3.2 where it is shown that the thermodynamic process is the dominant process for long adsorption time kinetics.

Table 3. Gibbs free energy for different micropollutants at a maximum uptake and Langmuir-Freundlich parameters of the isotherms at $298 \mathrm{~K}$.

\begin{tabular}{|c|c|c|c|c|c|}
\hline & OFX & DFN & BPA & CBZ & CAF \\
\hline$\Delta \mathrm{G}^{0}(\mathrm{~kJ} / \mathrm{mol})$ & -17.5 & -14.6 & -13.5 & -10.2 & -0.7 \\
\hline $\mathrm{Q}_{\max }(\mathrm{mmol} / \mathrm{g})$ & 0.7 & 1.35 & 1.72 & 1.59 & 1.9 \\
\hline $\mathrm{Q}_{\max }(\mathrm{mg} / \mathrm{g})$ & 253 & 400 & 393 & 376 & 369 \\
\hline $\mathrm{K}_{\mathrm{lf}}(\mathrm{L} / \mathrm{mmol})$ & 14930 & 7051 & 9612 & 2828 & 820 \\
\hline $\mathrm{n}$ & 1 & 1.12 & 1 & 1.15 & 0.85 \\
\hline
\end{tabular}

\section{2. Adsorption Kinetics}

In order to understand the adsorption mechanisms and to determine the key parameters governing adsorption, kinetics studies in binary or complex mixtures were performed. In some cases, competition effects were clearly visible as for example between DFN and CAF and between DFN and POL. Two regimes were detected: during the first five days the speciation and hydrodynamic volume of the adsorbates controlled the adsorption kinetics, with anionic adsorbates being adsorbed more slowly because of electrostatic repulsions. In a second step for longer times, polarity and therefore water solubility governed the adsorption uptake, with the less soluble and most hydrophobic DFN becoming easier to adsorb onto the hydrophobic carbon adsorbent surface (Figure 3 and Figure 4).

When approaching equilibrium, the adsorption of DFN occurred to the detriment of CAF or POL molecules, thus demonstrating that these molecules were in competition for some adsorption sites and that when DFN entered the pores, POL or CAF were removed from the pores. The molecules of CAF with a weak Gibbs energy of adsorption ( $\Delta \mathrm{G}^{0}$ abs $)$ were desorbed from some of their adsorption sites and replaced by the competing 
contaminants (DFN) interacting at lower energy with the ACC.

The adsorption behavior of DFN in the different binary systems showed that its adsorption capacity and adsorption kinetic were affected to a different extent. Firstly, one must consider the large size of the DFN molecule, in the range of $580 \AA^{3}$, as compared to the smaller molecules such as POL, PCP and CAF. More precisely, adsorbed DFN uptake was lowered especially when DFN was co-adsorbed with large species such as OFX and BPA (Figure 5 and Table 4).

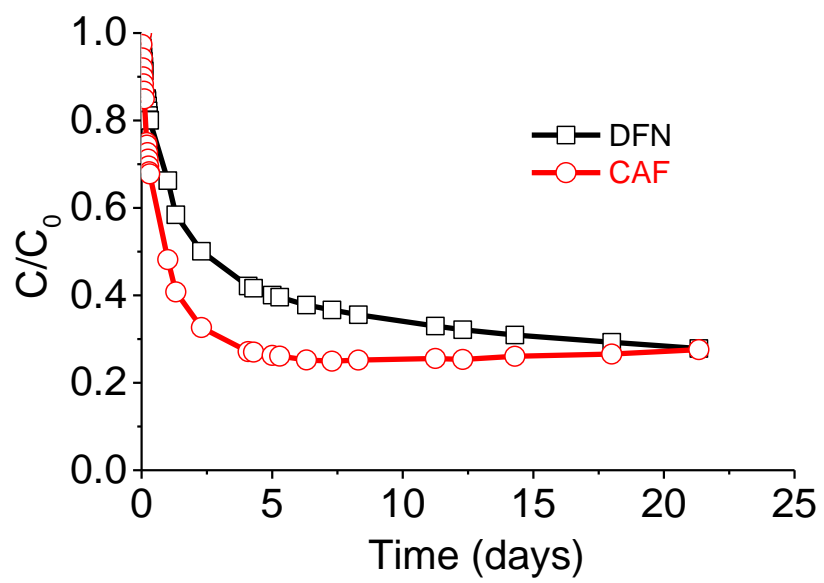

Figure 3. Adsorption of DFN and CAF (kinetics data).

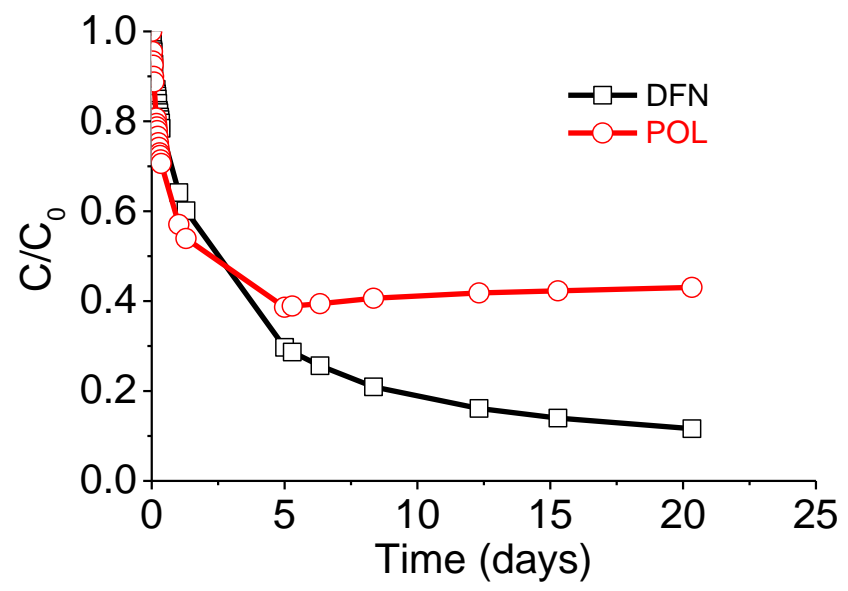

Figure 4. Adsorption of DFN and POL (kinetics data).

For co-adsorbates having the smallest hydrodynamic volumes, such as POL or CAF, the amounts of DFN adsorbed were less affected and high adsorption uptakes were measured.

These results showed the major role of adsorbate size during adsorption processes. For two adsorbates having different volumes, each of them could easily find an adsorption site in the porosity. For molecules that are large compared to the small size of the pores, it became more complicated, and adsorbates were in competition to reach the bigger micropores (Figure 6).

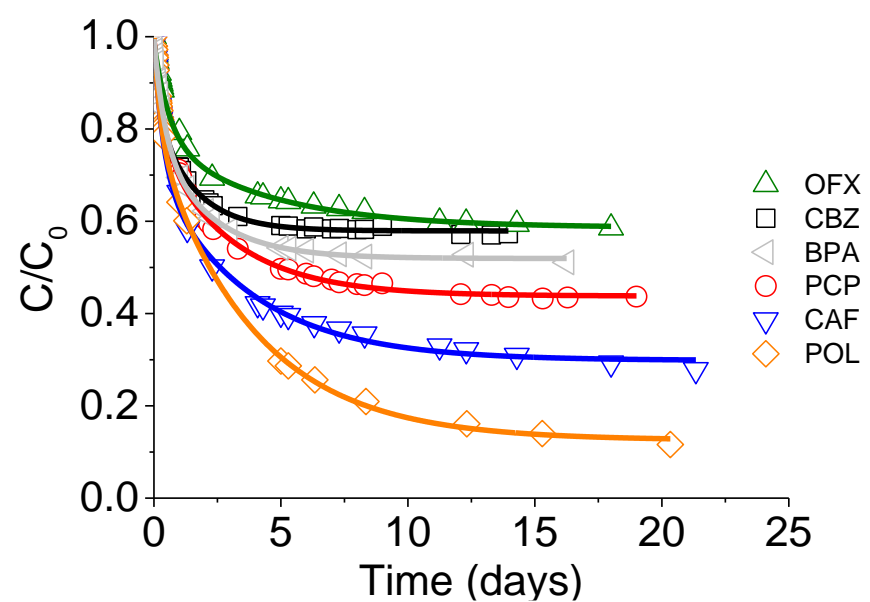

Figure 5. Adsorption kinetics of DFN in binary systems depending on the co-adsorbate.

Table 4. DFN adsorption characteristics.

\begin{tabular}{|c|c|c|}
\hline Co-adsorbate & $\begin{array}{c}\text { Qads DFN } \\
\text { mmol/g }\end{array}$ & $\begin{array}{c}\text { Qads Co-adsorbate } \\
\mathrm{mmol} / \mathrm{g}\end{array}$ \\
\hline POL & 1.03 & 0.70 \\
\hline PCP & 0.69 & 1.07 \\
\hline CAF & 0.82 & 0.90 \\
\hline CBZ & 0.51 & 0.82 \\
\hline BPA & 0.60 & 0.96 \\
\hline OFX & 0.49 & 0.27 \\
\hline
\end{tabular}

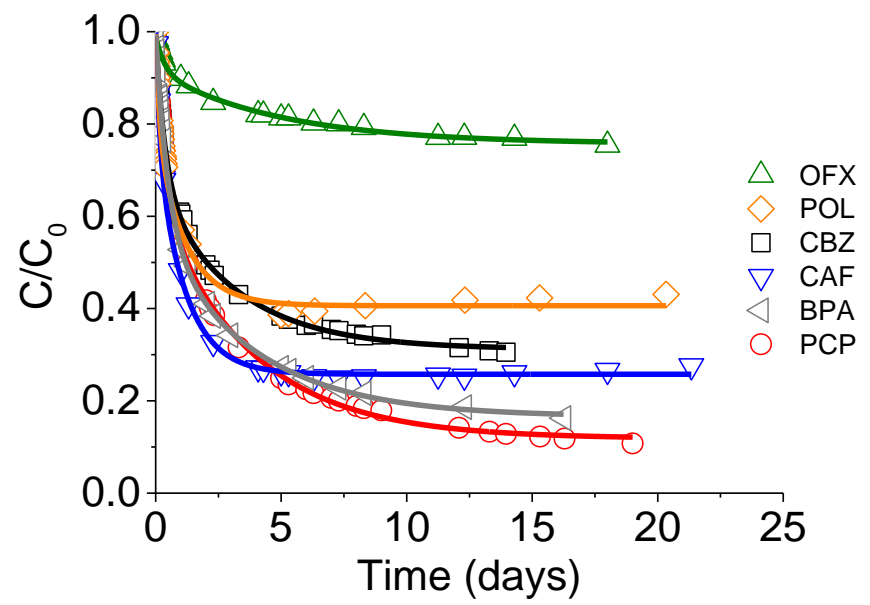

Figure 6. Adsorption kinetics of the co-adsorbate in binary systems with DFN.

When the adsorption kinetics were studied in a complex mixture containing the seven adsorbates, the same tendency was observed. The adsorbate size appeared to be the main parameter controlling the adsorption kinetics. The highest adsorption capacities 
were observed for the smallest organic molecules such as PCP and POL, whereas OFX and DFN which are large anionic molecules showed the slowest adsorption and the smallest uptake (Figure 7). The adsorption capacities could thus be directly correlated to the volume of the adsorbates.

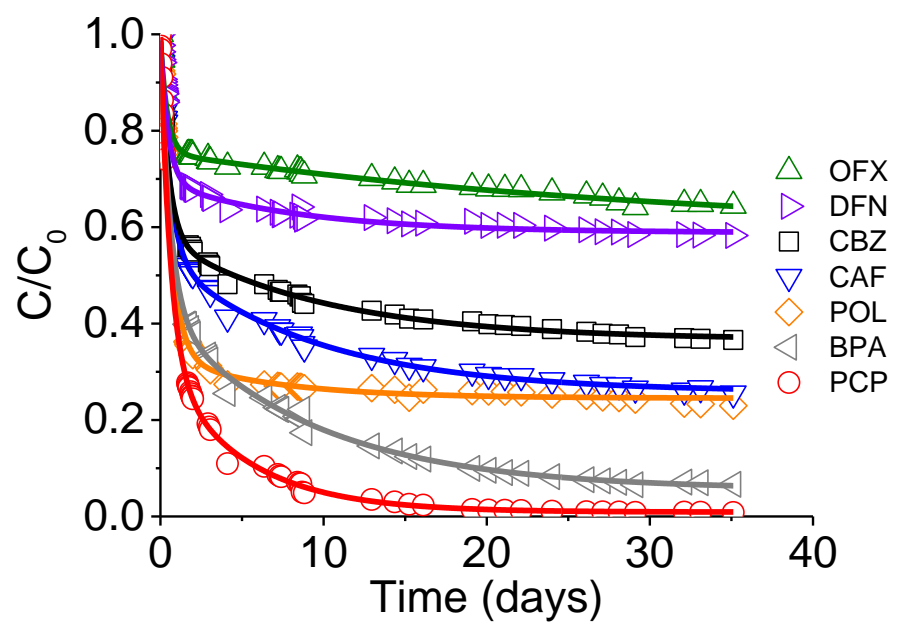

Figure 7. Adsorption kinetics of each pollutant in the complex mixture.

In order to complete the work, additional binary systems were studied with OFX in binary mixture and five co-adsorbates (PCP, BPA, DFN, CAF and CBZ). Like DFN, OFX was poorly adsorbed in the presence of PCP and BPA in the mixture (Table 5).

Table 5. OFX adsorption characteristics.

\begin{tabular}{|c|c|c|}
\hline Co-adsorbate & $\begin{array}{c}\text { Qads OFX } \\
\mathrm{mmol} / \mathrm{g}\end{array}$ & $\begin{array}{c}\text { Qads Co-adsorbate } \\
\mathrm{mmol} / \mathrm{g}\end{array}$ \\
\hline DFN & 0.11 & 0.40 \\
\hline BPA & 0.11 & 0.75 \\
\hline CBZ & 0.26 & 1.02 \\
\hline CAF & 0.41 & 0.95 \\
\hline PCP & 0.09 & 0.94 \\
\hline
\end{tabular}

OFX adsorption uptake at equilibrium was higher in the mixture with small molecules such as CAF and CBZ. Moreover, CAF single adsorption showed greater $\Delta \mathrm{G}^{0}$ than other molecules because of their small affinity with the carbon. The size effect was confirmed to be a key parameter driving the adsorption process in a binary system. Large molecules such as DFN and BPA diffused slowly into the pores because of steric hindrance whereas small molecules such as PCP and CAF diffused more rapidly and deeply inside the pores (Figure 8).

\section{3. Regeneration Under Polarization}

After loading activated carbon cloths with organic contaminants, an attempt at regeneration was conducted under cathodic polarization of the carbon cloth. Depending on the nature on the adsorbate, it was possible to perform the reversible desorption of the adsorbed species. Desorption was assumed to be performed through electrostatic repulsions occurring between the negatively charged carbon surface and the dissociated organic molecules, reinforced by the presence of the electrical field. High regeneration efficiency of about $60 \%$ was observed in the case of POL whereas for BPA (8.1 \%) or DFN (11.5\%) desorption was more difficult (Figure 9).

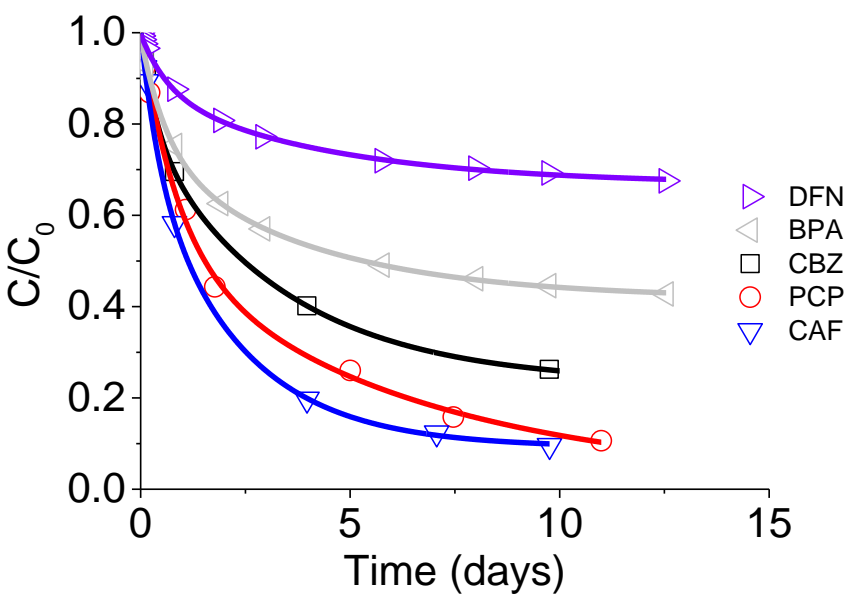

Figure 8. Adsorption kinetics of the co-adsorbates in binary systems with OFX.

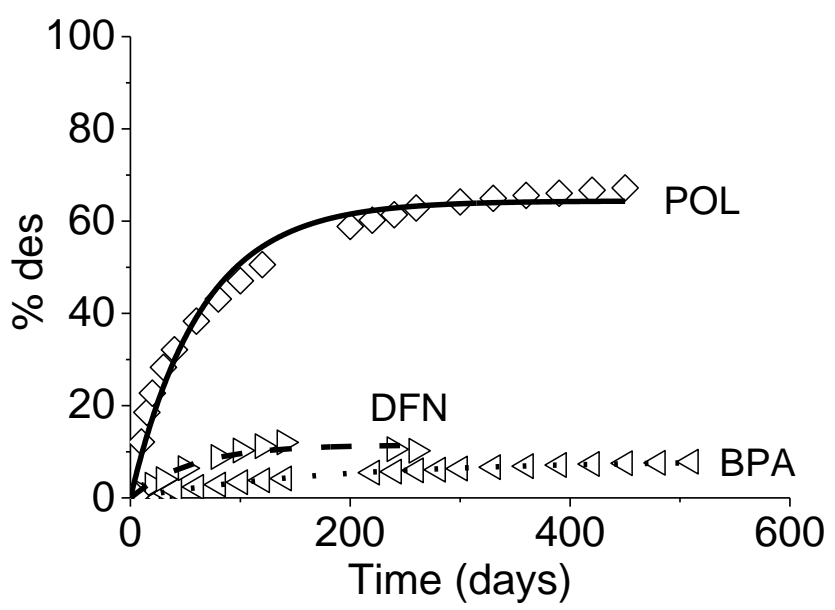

Figure 9. Regeneration percentages (\%) as a function of polarization time for POL, BPA and DFN.

It was assumed that for small adsorbates as POL reversible desorption became more easy, especially 
because of a better diffusion of the molecule inside the narrow pores $(<0.7 \mathrm{~nm})$. The incomplete regeneration was explained by either some steric blockage, especially for large molecules (DFN and BPA), inside the narrow pores or the trapping of the molecule in high energetics sites.

\section{Conclusion}

Activated carbon cloths are one of the most prevalent adsorbents able to trap emerging water contaminants. High adsorption capacities ranging from 250 to $400 \mathrm{mg} / \mathrm{g}$ were reached. The pollutants are mainly adsorbed in the narrow porosity by $\pi-\pi$ interactions. In two or seven-components systems, the adsorption kinetics of pollutants (CBZ, OFX, CAF, BPA, DFN, PCP and POL) studied at $10^{-4}$ mol. $L^{-1}$ on a microporous activated carbon cloth was found to be related to the molecular volume. In contrast, the solubility and the pollutant polarity were involved to a lesser extent. Small neutral molecules indeed showed the best adsorption capacities. Knowledge of the thermodynamic parameters such as $\Delta \mathrm{G}^{0}$ proved to be a useful tool to assess to what extent a molecule had been well adsorbed in a binary mixture at equilibrium. Furthermore, competition effects were highlighted. Molecules showing less negative Gibbs adsorption energy variation $\left(\Delta \mathrm{G}^{\circ}\right.$ ads $)$ were desorbed from some of their adsorption sites and replaced by the competing contaminants adsorbed with lower Gibbs energy variation. The adsorbent was partially regenerated through cathodic polarization. Steric blockages by large molecule sometimes take place and make the regeneration of the material more difficult to achieve.

\section{Acknowledgements}

The authors thank the French ANR for financial support.

\section{References}

[1] M. Huerta-Fontela, M. T. Galceran, J. MartinAlonso and F. Ventura, "Occurrence of psychoactive stimulatory drugs in wastewaters in north-eastern Spain," Science of the Total Environment, vol. 397, pp. 31-40, 2008.

[2] C. Stavrakakis, R. Colin, C. Faur, V. Héquet and P. Le Cloirec, "Analysis and behaviour of endocrine disrupting compounds in wastewater treatment plant," European Journal of Water Quality, vol. 39, no. 2, pp. 145-156, 2008.
[3] S. Snyder, C. Lue-Hing, J. Cotruvo, J. E. Drewes, A. Eaton, R. C. Pleus and D. Schlenk, Pharmaceuticals in the Water Environment, Report from NACWA and Association of Metropolitan Water Agencies: 2010.

[4] H. Guedidi, L. Reinert, J. M. Lévêque, Y. Soneda, N. Bellakhal and L. Duclaux, "Adsorption of ibuprofen from aqueous solution on chemically surface-modified activated carbon cloths," Carbon, vol. 54, pp. 432-443, 2013.

[5] C. O. Ania and F. Béguin, "Mechanism of adsorption and electrosorption of bentazone on activated carbon cloth in aqueous solutions," Water Research, vol. 41, pp. 3372-3380, 2007.

[6] S. Delpeux-Ouldriane, N. Cohaut and F. Béguin, "Electrochemical Removal of Ionogenic Pesticides Adsorbed on Activated Carbon Textiles," in Proceedings of the Annual World Conference on Carbon, Biarritz, France, 2009. vol. 3, pp. 1777-1784.

[7] S. Delpeux-Ouldriane and F. Béguin, "On Carbon Capture Reversible Assets," French Patent 1257895, August 20, 2012.

[8] M. Gineys, T. Kirner, N. Cohaut, F. Béguin and S. Delpeux-Ouldriane, "Simultaneous determination of pharmaceutical and pesticides compounds by reversed phase high pressure liquid chromatography," Journal of Chromatography and Separation Techniques, vol. 6, no. 6, 2015.

[9] S. Delpeux-Ouldriane, M. Gineys, N. Cohaut and F. Béguin, "The role played by local $\mathrm{pH}$ and pore size distribution in the electrochemical regeneration of carbon fabrics loaded with bentazon," Carbon, vol. 94, pp. 816-825, 2015. 